\title{
Evolving strategies for preserving the pulmonary valve during early repair of tetralogy of Fallot: Mid-term results
}

\author{
Vladimiro L. Vida, MD, PhD, ${ }^{a}$ Alvise Guariento, $\mathrm{MD},{ }^{\mathrm{a}}$ Biagio Castaldi, MD, ${ }^{\mathrm{b}}$ Matteo Sambugaro, MPH, \\ Massimo A. Padalino, MD, PhD, ${ }^{a}$ Ornella Milanesi, MD, ${ }^{b}$ and Giovanni Stellin, MD $^{\mathrm{a}}$
}

Background: The aim of the study was to evaluate our results with pulmonary valve (PV) preservation in selected patients with tetralogy of Fallot (TOF).

Methods: From January 2007, 69 patients who underwent early transatrial TOF repair were enrolled in the study. The patients were divided into 2 groups: PV preservation by PV annulus balloon dilation (group 1) and PV cusp reconstruction after annular incision (group 2).

Results: Thirty-four patients underwent a successful PV annular preservation (49\%). Median age at surgery was 113 days (range, 36-521 days) (group-1 vs group-2, $P=$ not significant). Median preoperative PV Z score was -3.15 (range, -0.95 to -5.62 ) (group-1 vs group- $2, P=.03$ ). Median intensive care unit and hospital stays were 3 and 10 days, respectively (group 1 vs group $2, P=$ not significant). Median follow-up time was 580 days (range, 189-1940 days) (group 1 vs group 2, $P=.08$ ). Two patients were reoperated for residual right ventricular outflow tract (RVOT) obstruction (1 in group 1 and 1 in group 2). The remaining patients are alive and well. Median peak RVOT gradient was $25 \mathrm{~mm} \mathrm{Hg}$ (range, 8-60 $\mathrm{mm} \mathrm{Hg}$ ) (group 1 vs group 2, $P=$ not significant). The degree of PV regurgitation in group 1 was none/mild in 24 patients $(80 \%)$ and moderate in $6(20 \%)$ and was none/mild in 8 patients $(25 \%)$, moderate in $11(34.4 \%)$, and severe in $13(28.6 \%)$ in group 2 $(P=.001)$. Median right ventricular fractional area change was $55 \%$ (range, $42 \%-70 \%)$ in group 1 and $50 \%$ (range, $40 \%-63 \%)$ in group $2(P=.003)$.

Conclusions: The integrity and function of the PV can be preserved in selected patients during early repair of TOF by concomitant balloon dilation, leading to a better mid-term right ventricular function. ( $\mathrm{J}$ Thorac Cardiovasc Surg 2014;147:687-96)

Tetralogy of Fallot (TOF) repair is now routine practice and can be achieved with low surgical risk in many pediatric cardiac centers. Correction via a right ventriculotomy with transannular right ventricular outflow tract (RVOT) patch reconstruction is still the most frequent approach. ${ }^{1}$

More recently, a transatrial approach has become the preferred procedure and it yields excellent early and mid-term results. ${ }^{2-10}$ The objective of a transatrial repair is to avoid (or minimize) structural damage to the subpulmonary pump, which has proved to be the Achilles' heel in the long term.

\footnotetext{
From the Department of Cardiac, Thoracic and Vascular Surgery, ${ }^{\mathrm{a}}$ Pediatric and Congenital Cardiac Surgery Unit, University of Padua, Padua, Italy; Department of Pediatrics, ${ }^{\mathrm{b}}$ Pediatric Cardiology Unit, University of Padua, Padua, Italy; Statistics Consultant, ${ }^{\mathrm{c}}$ Department of Cardiac, Thoracic and Vascular Surgery, University of Padua, Padua, Italy.

Disclosures: Authors have nothing to disclose with regard to commercial support.

Read at the 93rd Annual Meeting of The American Association for Thoracic Surgery, Minneapolis, Minnesota, May 4-8, 2013.

Received for publication May 2, 2013; revisions received Aug 30, 2013; accepted for publication Oct 11, 2013; available ahead of print Dec 5, 2013.

Address for reprints: Giovanni Stellin, MD, Department of Cardiac, Thoracic and Vascular Surgery, Chief of the Pediatric and Congenital Cardiac Surgery Unit, Via Giustiniani, 2 - 35100 Padua, Italy (E-mail: giovannistellin@unipd.it). $0022-5223 / \$ 36.00$

Copyright (c) 2014 by The American Association for Thoracic Surgery http://dx.doi.org/10.1016/j.jtcvs.2013.10.029
}

However, use of a transannular patch, although necessary in some cases, often results in pulmonary insufficiency with chronic right ventricular volume overload, leading inevitably to progressive right ventricular dilation and dysfunction that is associated with impaired functional capacity. ${ }^{1-5,8,9}$ Augmentation plasty of the pulmonary valve (PV) leaflets can avoid PV regurgitation early postoperatively, improving the short-term clinical outcome. ${ }^{3}$ Nonetheless, leaflet function often deteriorates over time resulting in progressive PV regurgitation. ${ }^{11-19}$

The interest in preserving PV function has stimulated surgeons to devise valve-sparing techniques for TOF repair. ${ }^{20-27}$ In recent years, we have combined, in selected cases, our routine early transatrial transpulmonary repair with intraoperative balloon dilation of the hypoplastic pulmonary annulus. ${ }^{22}$

The aim of this study is to evaluate the early and mid-term results of this approach to early repair of TOF, focusing on $\mathrm{PV}$ and right ventricular function in comparison with our standard transatrial/transpulmonary repair technique.

\section{METHODS}

Review of medical records and computerized hospital data was approved by the Clinical Investigation Committee from the University Hospital of Padua, and the procedures followed were in accordance with the institutional guidelines for retrospective record review and protection 


$$
\begin{aligned}
& \text { Abbreviations and Acronyms } \\
& \text { PV }=\text { pulmonary valve } \\
& \text { RCA }=\text { right coronary artery } \\
& \text { RV }=\text { right ventricular } \\
& \text { RVFAC }=\text { right ventricle fraction of area change } \\
& \text { RVOT }=\text { right ventricular outflow tract } \\
& \text { TOF }=\text { tetralogy of Fallot } \\
& \text { VSD }=\text { ventricular septal defect }
\end{aligned}
$$

of patient confidentiality. Individual consent was not obtained by patients enrolled in this study. Patients are not identified, and the chairperson of the Ethics Committee of our institution consented to publication of their data.

From June 2007, all patients who underwent repair of TOF at our institution were enrolled in the study. Patients with mild forms of TOF who did not require surgical manipulation of the PV, TOF with severe pulmonary valve stenosis and diminutive pulmonary artery branches with aortopulmonary collaterals who were treated by right ventricle-pulmonary artery conduit interposition, TOF with absent PV, double-outlet right ventricle, and adult patients undergoing repair of TOF were excluded.

Our standard institutional policy for TOF repair in early infancy since June 1991 (usually in patients $\leq 3$ months of age) includes (1) the transatrial/transpulmonary approach to the subpulmonary outflow tract, (2) incision of the PV annulus with minimal right ventriculotomy (3-5 mm) when necessary, and (3) transatrial closure of the ventricular septal defect using an autologous pericardial patch. ${ }^{24}$

PV function is reestablished by the use of a pulmonary homograft monocusp patch, tailored at the annular level, to match the posterior natural leaflets (up to 2007) or by adding either a polytetrafluoroethylene $(0.1 \mathrm{~mm}$ diameter) or CorMatrix ECM Technology (CorMatrix Cardiovascular Inc, Sunnyvale, Calif) leaflet under the RVOT enlargement patch.

Since 2007, we have attempted to preserve the PV annulus anatomy and function by intraoperative PV balloon dilation in selected patients. After a longitudinal pulmonary arteriotomy, the PV orifice was sized on the beating heart using a Hegar dilator (Table 1) to assess the effective diameter of the $\mathrm{PV}$ orifice. Valvular commissurotomy was routinely performed up to the sinutubular junction and the valve was sized again with a Hegar dilator to check the real annular diameter and to calculate the effective PV $\mathrm{Z}$ score. ${ }^{28}$ After the subpulmonary muscular obstruction was relieved through the tricuspid valve up to the hinges of the PV leaflets, and the ventricular septal defect (VSD) was closed, a valvuloplasty balloon was then introduced through the tricuspid valve across the PV orifice and inflated under direct vision until the inner pressure reached 10 atmospheres. We chose short $(2 \mathrm{~cm})$, high-pressure ( $>10$ atmospheres), noncompliant balloons, ${ }^{22}$ sized according to the calculated size of the PV orifice relative to the body surface area of the patient. At the end of the procedure, the diameter of the PV was sized again with an appropriate Hegar dilator to check the results of the dilation, and the valve was carefully examined to exclude any possible iatrogenic lesion (Figures 1 and 2).

This new technique was initially used in selected patients with milder forms of TOF ( $\mathrm{Z}$ score $\geq-3$ ). The criteria for using this approach have recently evolved to include patients with a $Z$ score of -4 or lower. When dealing with a hypoplastic PV annulus ( $Z$ score between -3 and -4 ) after an initial PV commissurotomy followed by PV balloon dilation (up to the expected PV dimension for the body surface area), the PV leaflets, which have often been separated at the commissure level, are reconstructed by carefully delaminating the PV hinge point with a fine scalpel down to the right ventricular (RV) epicardium, thus extending the leaflet's coaptation area (Figures 1 and 2). Subsequently, the extended leaflets are resuspended at the level of the new PV commissure or further extended by means of a small prosthetic (biological) patch and then resuspended. An appropriate Hegar dilator for the PV size ( $\mathrm{PV} \mathrm{Z}$ score $=0)$ is passed through the new PV annulus.

Particular care is taken to remove any possible RVOT obstruction up to the subannular level by combining transatrial, transtricuspid, muscle band resection and a further transpulmonary residual muscle band excision through the PV annulus, before and after balloon dilation.

\section{Clinical Data and Outcomes}

Transesophageal or epicardial echocardiography was used to monitor the immediate surgical results. Patients were evaluated by echocardiography (iE33 xMATRIX Echocardiography System, Philips Medical System, Andover, Mass) at hospital discharge and during outpatient follow-up.

Patients who were followed for less than 6 months after surgery were excluded from the analysis ( $n=7$ patients, 4 of whom underwent PV preservation and 3 a standard TOF repair). Two patients who required a reoperation for residual RVOT obstruction after the initial repair were also excluded.

RVOT obstruction was quantified using Doppler echocardiography and classified as mild ( $<20 \mathrm{~mm} \mathrm{Hg}$ ), moderate (between 20 and $40 \mathrm{~mm} \mathrm{Hg}$ ), or severe ( $>40 \mathrm{~mm} \mathrm{Hg}$ ). Pulmonary regurgitation was quantified as (1) nonemild, (2) moderate, or (3) severe. ${ }^{29,30}$ Right ventricular function was measured using the fractional area change (RVFAC). ${ }^{31,32}$ The twodimensional echo images were retrospectively reviewed in the echocardiography laboratory by a single staff pediatric cardiologist, who was blinded to the surgical procedure.

The primary outcome of this study was to assess the effectiveness of the PV preservation technique by focusing on mid-term PV and RV function. These results were compared with those of our standard transatrial repair with transannular patch (TAR-TAP) performed during the same time interval (including patients who had a failed $\mathrm{PV}$ preservation and who were converted to a standard TOF repair) (group 2).

Categorical variables are shown as absolute frequencies and percentages. Quantitative variables were summarized as the median and range. When quantitative variables were not normally distributed (assessed by the Shapiro-Wilk normality test), comparison between groups was done using the Kruskal-Wallis test. Categorical variables were compared using the $\chi^{2}$ test or the Fisher exact test. Linear regression analysis was used to test the relationship between residual RVOT obstruction or PV regurgitation at follow-up and ventricular function. All reported $P$ values are 2 -sided. Statistical analysis was performed using Stata software (release 10.0 for Windows; Stata Corporation, College Station, Tex).

\section{RESULTS}

Sixty-nine patients were included in our study. Median age at surgery was 113 days (range, 36-521 days). In 39 patients, we attempted to preserve PV integrity. The remaining 30 patients, most of them at the beginning of our experience, underwent a standard transatrial/transpulmonary repair. In accordance with our policy of early repair, none of the patients had previously undergone a palliative procedure except for 1 patient from another institution in whom a stent had been placed in the patent ductus arteriosus at 1 month of age for severe arterial oxygen desaturation.

The median preoperative transcutaneous oxygen saturation was $93 \%$ (range, $80 \%-100 \%$ ). Three patients $(4.3 \%)$ had repeated cyanotic spells. The preoperative transcutaneous oxygen saturation was significantly higher $(P=.03)$ in patients who had preservation of the $\mathrm{PV}$ (Table 1). 
TABLE 1. Preoperative, intraoperative, and postoperative data $(n=69$ patients $)$

\begin{tabular}{|c|c|c|c|}
\hline & \multicolumn{2}{|c|}{ Surgical groups } & \multirow[b]{2}{*}{$P$ value } \\
\hline & PV dilatation group $(n=34)$ & Standard TA/TP repair group $(\mathbf{n}=\mathbf{3 5})$ & \\
\hline Median age at surgery, $\mathrm{d}$ (range) & $115(36-521)$ & $113(65-454)$ & .41 \\
\hline Men, $\mathrm{n}(\%)$ & $19(55.9)$ & $17(48.6)$ & .7 \\
\hline Median weight at surgery, $\mathrm{kg}$ (range) & $5.7(4.6-10)$ & $6.0(3.2-10.1)$ & .92 \\
\hline Median body surface area, $\mathrm{m}^{2}$ (range) & $0.3(0.25-0.46)$ & $0.3(0.22-0.45)$ & .46 \\
\hline Median two-dimensional echo PV annulus, mm (range) & $6.8(5.5-8.8)$ & $6(4-9.5)$ & .02 \\
\hline Median PV Z score on 2 dimensions, $\mathrm{n}(\%)$ & $-2.95(-0.95$ to -4.06$)$ & $-3.35(-1.54$ to -5.62$)$ & .03 \\
\hline Median preoperative transcutaneous $\mathrm{O}_{2}$ saturation, $\%$ (range) & $94(80-100)$ & $90(80-100)$ & .03 \\
\hline Median preoperative RVOT gradient, $\mathrm{mm} \mathrm{Hg}$ (range) & $67(40-87)$ & $70(55-93)$ & .12 \\
\hline Coronary anomalies, $\mathrm{n}(\%)$ & $1(2.9)$ & $4(11.4)$ & .36 \\
\hline Median effective PV orifice, ${ }^{*} \mathrm{~mm}$ (range) & $5(4-8)$ & $5(3-8)$ & .0015 \\
\hline Median postcommissural annulus, $\mathrm{mm}$ (range) & $7(6-9)$ & & na \\
\hline Median CPB time, min (range) & $125(93-200)$ & $158(104-237)$ & .0001 \\
\hline Median crossclamp time, min (range) & $76(45-118)$ & $75(48-114)$ & .93 \\
\hline \multicolumn{4}{|l|}{ RVP/SBP after CPB discontinuation, $\mathrm{n}(\%)$} \\
\hline$\leq 1 / 3$ & $8(23.5)$ & $10(28.6)$ & \\
\hline$\leq 1 / 2$ & $19(55.9)$ & $21(60)$ & .56 \\
\hline$\leq 3 / 4$ & $7(20.6)$ & $4(11.4)$ & \\
\hline Median ICU stay, d (range) & $3(1-8)$ & $3(1-12)$ & .46 \\
\hline ICU complications, $\mathrm{n}(\%)$ & $11(32.4)$ & $8(22.9)$ & .54 \\
\hline Postoperative junctional tachycardia, n (\%) & $6(17.6)$ & $1(2.9)$ & .04 \\
\hline Postoperative low output syndrome, n (\%) & $3(8.8)$ & $3(8.6)$ & .99 \\
\hline Median hospitalization, d (range) & $10(7-43)$ & $10.5(7-31)$ & .7 \\
\hline
\end{tabular}

$P V$, Pulmonary valve; $T A / T P$, transatrial/transpulmonary; $R V O T$, right ventricle outflow tract; $n a$, not applicable; $C P B$, cardiopulmonary bypass; $R V P$, right ventricular pressure; $S B P$, systemic blood pressure; $I C U$, intensive care unit. *Sized by Hegar dilators before any maneuver of the pulmonary valve.

By preoperative echocardiogram, the median $\mathrm{Z}$ score for the PV diameter was -3.15 (range, -0.95 to -5.62 ); the median peak gradient across the pulmonary outflow tract was $69 \mathrm{~mm} \mathrm{Hg}$ (range, 40-93 $\mathrm{mm} \mathrm{Hg}$ ).

At the time of surgery, the PV was found to be bicuspid in 59 patients $(85.5 \%)$, tricuspid in $6(8.7 \%)$, and unicuspid in $4(5.8 \%)$. Five patients $(7.2 \%)$ had coronary artery anomalies including (1) right coronary artery (RCA) from the left anterior descending crossing the RVOT $(\mathrm{n}=2)$, (2) major conal branch coronary artery from the RCA crossing the RVOT ( $n=2)$, and (3) anomalous origin of the RCA from the main pulmonary artery trunk crossing the RVOT $(n=1)$.

In 34 of the 39 patients considered to be suitable candidates $(87 \%)$, it was possible to preserve the PV annulus. In the remaining 5 patients, we converted our initial attempt at PV dilatation into a standard transatrial/transpulmonary repair including reconstruction of the pulmonary leaflets and patch augmentation of the pulmonary trunk. The PVsparing procedure failed because of tearing of the hinges of the valve leaflets caused by use of an oversized balloon catheter early in our experience in 3 patients and a low PV Z score $(<-4)$ in 2 patients. Preoperative variables according to the surgical group and the type of repair and preoperative PV morphology are listed in Table 1.

As previously described, ${ }^{22}$ an in-series balloon strategy was performed in $15 / 34$ patients $(44.1 \%)$. This technique consisted of using balloon catheters of increasing diameter to allow progressive stretching and dilation of the PV annulus to eventually reach the expected value of PV annulus for the body surface area of the patient and to prevent accidental tears of the PV annulus. Patients treated by an in-series balloon dilation had a lower preoperative median PV $\mathrm{Z}$ score $(-3.56$, range, $-2-28$ to -4.06 vs -2.39 , range, $-0-95$ to -3.74$)(P=.0024)$.

Eighteen patients required an additional surgical maneuver on the dilated PV (52.9\%), which included (1) resuspension of the leaflets $(n=4)$; (2) PV leaflets delamination and resuspension $(n=11)$; or (3) leaflets delamination, leaflet patch augmentation, and resuspension $(\mathrm{n}=3)$.

Median cardiopulmonary bypass (CPB) time was 134 minutes (range, 93-237 minutes) and was higher in patients who underwent classic TOF repair $(P=.0001$, Table 1$)$. Median crossclamp time was 76 minutes (range, 45-118 minutes) and did not differ significantly between groups.

At the end of the CPB procedure, the RV pressure was measured by direct puncture and was less than one-third of the systemic pressure in 18 patients $(26.1 \%)$, less than half of the systemic pressure in 40 patients $(58 \%)$, and less than three-quarters of the systemic pressure in 11 patients $(15.9 \%)$; it did not differ significantly between groups (Table 1). 


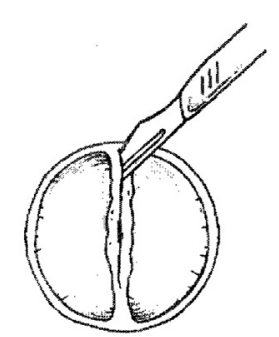

A

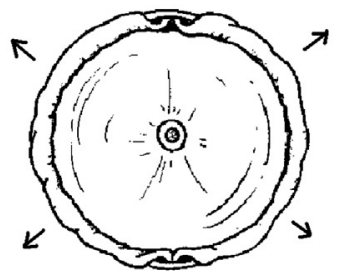

B

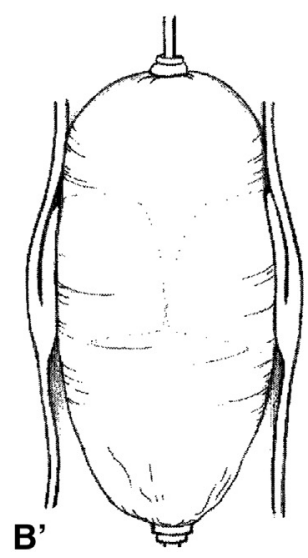

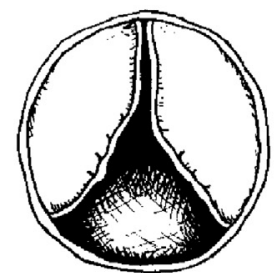

C

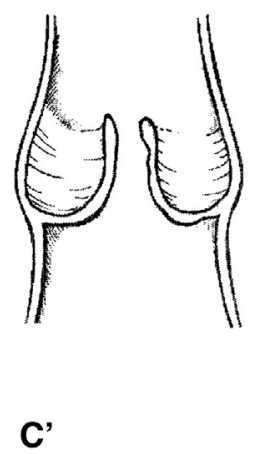

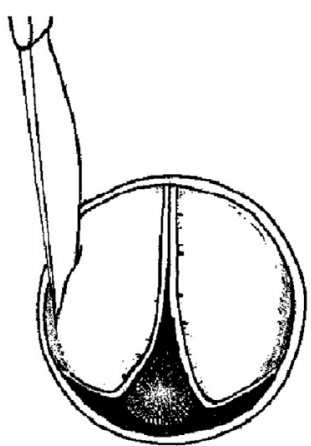

D

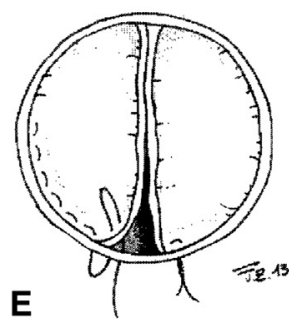

FIGURE 1. Cartoon showing the balloon dilation technique: A, Protective commissurotomy; $B, B^{\prime}$, balloon dilation of the pulmonary valve annulus; $\mathrm{C}, \mathrm{C}^{\prime}$, status after balloon dilation showing the gap of pulmonary valve tissue after the dilation procedure; $\mathrm{D}, \mathrm{D}^{\prime}$, leaflet delamination procedure (to increase the pulmonary valve coaptation surface); E, resuspension plasty (to avoid leaflet prolapse).

Median time in intensive care was 3 days (range, 1-12 days). The incidence of temporary postoperative junctional tachycardia was significantly higher in patients who underwent PV preservation $(P=.04$, Table 1$)$.

The median RVOT gradient did not differ significantly between the 2 groups at the discharge echocardiogram (Table 2). However, patients who had undergone the PVsparing procedure had significantly less pulmonary regurgitation $(P=.0001$, Table 2$)$.

\section{Follow-up}

Median follow-up time was 580 days (range, 189-1940 days), and was longer for patients who underwent standard repair $(P=.08$, Table 3$)$. Two patients required reoperation for residual RVOT obstruction greater than $50 \mathrm{~mm} \mathrm{Hg}, 1$ after PV preservation early in our experience and 1 after standard TOF repair. The remaining 67 patients are asymptomatic, in sinus rhythm, and doing well without medication.

At the most recent two-dimensional echocardiogram, the median RVOT gradient was $22 \mathrm{~mm} \mathrm{Hg}$ (range, 7-45 mm) and did not differ significantly between the 2 groups (Table 3$)$. The severity of PV regurgitation was significantly less in the PV preservation group $(P=.001$, Table 3$)$.
In the PV preservation group, there was a significant correlation between preoperative $\mathrm{PV} \mathrm{Z}$ score and the severity of $\mathrm{PV}$ regurgitation at follow-up $(P=.003)$. Five of 6 patients with moderate $\mathrm{PV}$ regurgitation had a preoperative $\mathrm{Z}$ score less than -3.5 .

There was also a significant correlation $(P<.001)$ between the grade of PV regurgitation and RV function at follow-up (Figure 3). The RVFAC was significantly higher in patients who underwent $\mathrm{PV}$ preservation $(P=.02)$ (Table 3).

The $\mathrm{Z}$ score of the PV orifice (calculated only in patients who underwent PV preservation) at the last follow-up twodimensional echo evaluation seemed to be adequate for the patient's body surface area, with a median valued of 0.1 (range, -0.3 to +0.7 ).

\section{DISCUSSION}

Continuous improvements in surgical techniques and postoperative management have made the repair of TOF feasible in early infancy with a low risk. ${ }^{5,17-20}$ Despite awareness of the late consequences of PV regurgitation, ventriculotomy with transannular patch placement remains the most prevalent technique for repair of patients with TOF. ${ }^{5}$ 

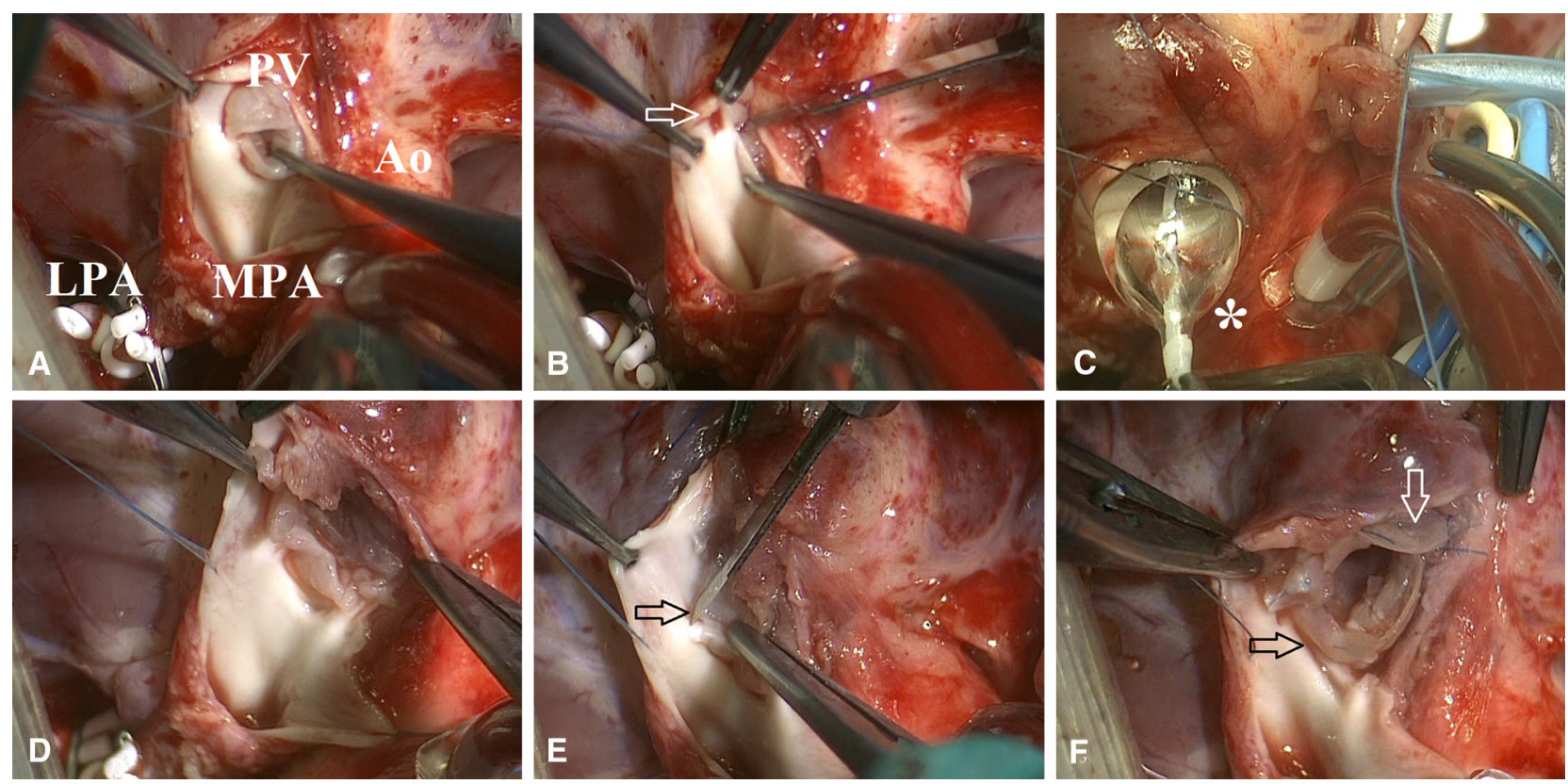

FIGURE 2. Intraoperative images of a 3.5-month-old boy with tetralogy of Fallot showing the pulmonary valve preservation technique. A, The effective PV orifice; B, the protective commissurotomy (white arrow); C, balloon dilation of the PV (*, balloon catheter); D, PV after balloon dilation; E, PV leaflet delamination (black arrow); F, leaflet patch augmentation (black and white arrows) and resuspension. PV, Pulmonary valve; Ao, ascending aorta; LPA, left pulmonary artery; $M P A$, main pulmonary artery.

After long-term follow-up of conventional TOF repair, other centers ${ }^{17-26}$ have developed techniques with the aim of limiting PV regurgitation, thus preserving PV function and eliminating or minimizing a large right ventriculotomy, with the aim of avoiding late RV dilation and dysfunction, and the occurrence of ventricular arrhythmias. $^{12,13}$

Since the early 1990 s, ${ }^{3-24}$ we have developed different surgical approaches at our institution, with the aim of achieving the best surgical result in the long-term but maintaining a low operative risk.
In the early 1990s, we first adopted an elective primary surgical repair in early infancy, combined with a transatrial transpulmonary approach that has eliminated the deleterious effects of a 2-stage repair. ${ }^{3}$ Subsequently, in the mid-1990s, we electively included the use of a monocusp patch (autologous pericardium, a polytetrafluoroethylene patch of pulmonary homograft) when a transannular patch is required, to achieve valvular competence, thus producing better short-term and mid-term surgical outcomes., ${ }^{3,6-11}$

During the past few years, the long-term results of standard TOF repair reported with increasing frequency cases

TABLE 2. Two-dimensional echocardiographic data at discharge

\begin{tabular}{|c|c|c|c|}
\hline & \multicolumn{2}{|c|}{ Surgical group } & \multirow[b]{2}{*}{$P$ value } \\
\hline & PV dilatation group $(n=34)$ & Standard TA/TP repair group $(n=35)$ & \\
\hline \multicolumn{4}{|l|}{ Degree of TV regurgitation, $\mathrm{n}(\%)$} \\
\hline Grade 1 (none-mild) & $30(91.2)$ & $33(94.3)$ & \\
\hline Grade 2 (moderate) & $3(8.8)$ & $2(5.7)$ & .48 \\
\hline Grade 3 (severe) & - & - & \\
\hline Median RVOT gradient, mm Hg (range) & $29(18-50)$ & $25(12-50)$ & .18 \\
\hline \multicolumn{4}{|l|}{ RVOT gradient grade, $\mathrm{n}(\%)$} \\
\hline Grade $1(<20 \mathrm{~mm} \mathrm{Hg})$ & $1(2.9)$ & $7(20)$ & \\
\hline Grade $2(20-40 \mathrm{~mm} \mathrm{Hg})$ & $30(88.2)$ & $26(77.1)$ & .07 \\
\hline Grade $3(>40 \mathrm{~mm} \mathrm{Hg})$ & $3(8.8)$ & $1(2.9)$ & \\
\hline \multicolumn{4}{|l|}{ Degree of PV regurgitation, $\mathrm{n}(\%)$} \\
\hline Grade 1 (none-mild) & $30(88.2)$ & $14(40)$ & \\
\hline Grade 2 (moderate) & $4(11.8)$ & $9(25.7)$ & .0001 \\
\hline Grade 3 (severe) & - & $12(34.3)$ & \\
\hline
\end{tabular}

$P V$, Pulmonary valve; $T A / T P$, transatrial/transpulmonary; $T V$, tricuspid valve; $R V O T$, right ventricle outflow tract. 
TABLE 3. Two-dimensional echocardiographic data at follow-up

\begin{tabular}{|c|c|c|c|}
\hline & \multicolumn{2}{|c|}{ Surgical group } & \multirow[b]{2}{*}{$P$ value } \\
\hline & PV dilatation group $(\mathbf{n}=\mathbf{3 0})$ & Standard TA/TP repair group $(n=32)$ & \\
\hline Median follow-up time, d (range) & $432.5(189-1940)$ & $711.5(189-1492)$ & .08 \\
\hline \multicolumn{4}{|l|}{ Degree of TV regurgitation, $\mathrm{n}(\%)$} \\
\hline Grade 1 (none-mild) & $30(100)$ & $32(100)$ & \\
\hline Grade 2 (moderate) & - & - & na \\
\hline Grade 3 (severe) & - & - & \\
\hline Median RVOT gradient, mm Hg (range) & $23.5(8-40)$ & $22(7-45)$ & .85 \\
\hline \multicolumn{4}{|l|}{ RVOT gradient grade, n (\%) } \\
\hline Grade $1(<20 \mathrm{~mm} \mathrm{Hg})$ & $18(60)$ & $18(56.3)$ & \\
\hline Grade $2(20-40 \mathrm{~mm} \mathrm{Hg})$ & $12(40)$ & $12(37.5)$ & .37 \\
\hline Grade $3(>40 \mathrm{~mm} \mathrm{Hg})$ & - & $2(6.3)$ & \\
\hline PV Z score, n (range) & $-0.1(-0.3$ to +0.7$)$ & - & - \\
\hline \multicolumn{4}{|l|}{ Degree of PV regurgitation, $\mathrm{n}(\%)$} \\
\hline Grade 1 (none-mild) & $24(80)$ & $8(25)$ & \\
\hline Grade 2 (moderate) & $6(20)$ & $11(34.4)$ & .001 \\
\hline Grade 3 (severe) & - & $13(40.6)$ & \\
\hline Median RVFAC, n (\%) & $55(42-70)$ & $50(40-63)$ & .003 \\
\hline
\end{tabular}

$P V$, Pulmonary valve; $T A / T P$, transatrial/transpulmonary; $T V$, tricuspid valve; $n a$, not applicable; $R V O T$, right ventricle outflow tract; $R V F A C$, right ventricle fraction of area change.

of RV failure, which was produced mainly by free PV regurgitation; at the same time, we were impressed by the results that our colleagues were achieving on PV dilatation in isolated PV stenosis. Therefore, we embarked on a new surgical approach that combines all the previous surgical techniques and includes the preservation of the native PV.

We were confident about the recently acquired techniques on aortic valve preservation, which could be transferred to preserving PVs in patients with TOF, consisting of leaflet delamination, shaving, leaflet augmentation, tear repair, and new commissure resuspension. It is obvious that such techniques have shown better results when applied in a low pressure system compared with the systemic system.

Our study has demonstrated that the PV annulus and function can be preserved in selected patients undergoing early surgical repair of TOF, by combining a transatrial/ transpulmonary subpulmonary muscular resection, VSD closure, without transgressing on the ventriculo-arterial junction.

During our early experience, we limited such a technique to patients with a PV Z score of -3 or higher only. More recently, as our experience has expanded, we have extended the use of this technique to patients with more severe PV annulus hypoplasia ( $\mathrm{Z}$ score $\leq-4$ ). We believe that our success is linked to the in-series balloon dilation strategy, which allows more progressive stretching of the PV annulus fibers (thus avoiding unexpected ruptures). Furthermore, the new concept of PV leaflet delamination allowed us to increase the PV leaflets coaptation area to fill the gap created at the commissure level after balloon dilation. In addition, an aggressive PV plasty was performed, especially in patients with a small PV annulus, to achieve a good valve that was competent at the end of the surgical repair. It is obvious that complete resection of obstructing muscle tissue, up to the PV annulus, needs to be performed before and after PV balloon dilation.

Soon after the crossclamp, the PV was initially carefully inspected and sized. A protective careful incision at each commissure was carried out in all patients before balloon dilation, with the aim of allowing the PV annulus to dilate at the commissure level, thus avoiding any damage to the

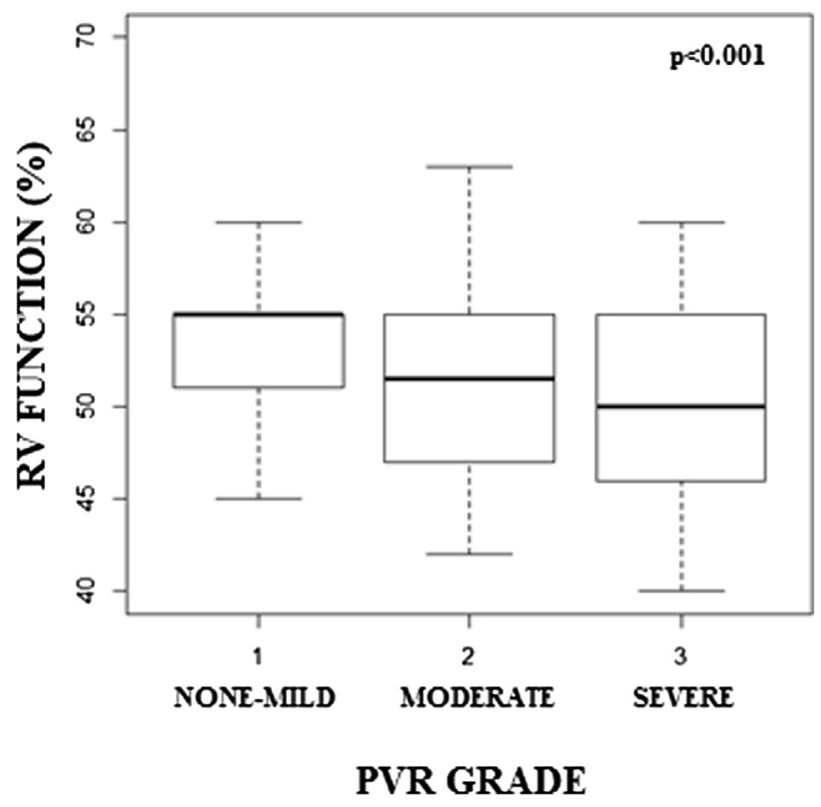

FIGURE 3. Linear regression analysis showing the correlation $(P<.001)$ between the grade of pulmonary valve regurgitation $(P V R)$ and right ventricular $(R V)$ function at follow-up. 
PV leaflets. Care must also be taken when choosing the appropriate size of the dilating balloon. We have used high-pressure noncompliant balloons. The radial force of the dilation is distributed around the circumference of the $\mathrm{PV}$, thus obtaining homogeneous stretching of the elastic fibers of the PV annulus; these are important principles that can never be achieved by forcing a Hegar dilator through the PV annulus (longitudinal force), as others have reported. $^{20}$

Our balloons were systematically inserted through the RVOT into the PV and held in that position to avoid balloon dislodgement during dilation. In contrast to our interventional cardiologist colleagues, who often oversize the balloon when dilating PVs, we found that it is important not to oversize the balloon. Excessive dilation in an open field can overstretch the valve, inevitably leading to irreparable PV damage.

According to our mid-term results, preservation of the PV was possible in almost half of the cases of repaired TOF treated in our institution since 2007. Our positive results allowed us to achieve significantly better PV competence and RV function in the mid-term. These results were optimal in patients with a $\mathrm{Z}$ score of -3 or higher. Recently, however, we extended the application of this technique to patients with a PV Z score down to -4 . The smaller the annulus, the more frequently lesions on the PV were observed. Nevertheless, we could repair them promptly, eventually obtaining a competent PV.

A 2-stage repair has a hypothetical advantage of a higher PV preservation rate. ${ }^{33,34}$ Surgical palliation by means of a modified Blalock-Taussig shunt continues to be indicated in many centers for patients with a low body weight or in patients with diminutive pulmonary arteries. It allows the growth of the pulmonary arteries and of the PV, thus possibly allowing a higher rate of PV preservation, however it is associated with significant morbidity and mortality, ${ }^{33}$ both early and in the long term. The use of RVOT stenting has also been advocated as an alternative approach to allow the growth of the pulmonary arteries in symptomatic neonates with TOF, however, it may jeopardize PV integrity, possibly precluding its preservation. Percutaneous stabilization of the arterial duct, with highly flexible coronary stents, has been introduced and developed since 2003. ${ }^{34,35}$ This technique has been shown to be safe and effective in promoting significant and balanced growth of the pulmonary arteries. This technique may be considered in the future for more severe forms of TOF as a bridge to complete repair, especially in symptomatic patients, with the aim of combining the development of the pulmonary vascular tree and the PV apparatus, possibly leading to a higher PV preservation outcome. ${ }^{35}$ In our experience, truly hypoplastic pulmonary arteries have been rarely encountered in classic TOF, in the absence of a systemicpulmonary collateral circulation. When present, they are usually confined to those cases with intrinsic pulmonary artery disease.

This study has some limitations. It is a retrospective study. The population with treated TOF is still small and the follow-up time is still short, therefore we cannot reach definitive conclusions about the validity of this new surgical technique. Nonetheless, our early and mid-term results with this new technique are encouraging and superior to those obtained after standard treatment of TOF at our institution. We are still in the learning phase of a new technique. In every case that we deal with, we include new techniques, which are important not only for preserving the integrity of the PV annulus but also for its reconstruction, so that sufficient PV dilation is achieved.

In conclusion, $\mathrm{PV}$ function can be preserved during early TOF repair and this can help to avoid long-standing RV dysfunction, and possibly future interventions for treating PV regurgitation, thus potentially changing the natural history of patients with repaired TOF. We have recently further expanded the applicability of the technique to patients with an increasingly smaller PV annulus; in-series balloon dilation and the delamination technique are key to achieving acceptable PV competence after the operation and at follow-up. It is our policy now to attempt PV dilation in all patients with classic TOF patients with a $\mathrm{Z}$ score of -4 or higher. When total valve preservation cannot be achieved, the ventricular muscle incision is usually minimal and acceptable PV competence can always be achieved.

\section{References}

1. Al Habib HF, Jacobs JP, Mavroudis C, Tchervenkov CI, O’Brien SM, Mohammadi S, et al. Contemporary patterns of management of tetralogy of Fallot: data from the Society of Thoracic Surgeons Database. Ann Thorac Surg. 2010;90:813-9.

2. Sarris GE, Comas JV, Tobota Z, Maruszewski B. Results of reparative surgery for tetralogy of Fallot: data from the European Association for Cardio-Thoracic Surgery Congenital Database. Eur J Cardiothorac Surg. 2012;42:766-74.

3. Stellin G, Milanesi O, Rubino M, Michielon G, Bianco R, Moreolo GS, et al. Repair of tetralogy of Fallot in the first six months of life: transatrial versus transventricular approach. Ann Thorac Surg. 1995;60:S588-91.

4. van den Berg J, Hop WC, Strengers JL, de Jongste JC, van Osch-Gevers L, Meijboom FJ, et al. Clinical condition at mid-to-late follow-up after transatrial-transpulmonary repair of tetralogy of Fallot. J Thorac Cardiovasc Surg. 2007;133:470-7.

5. Jonas RA. Early primary repair of tetralogy of Fallot. Semin Thorac Cardiovasc Surg Pediatr Card Surg Annu. 2009;39-47.

6. Sfyridis PG, Kirvassilis GV, Papagiannis JK, Avramidis DP, Ieromonachos CG, Zavaropoulos PN, et al. Preservation of right ventricular structure and function following transatrial-transpulmonary repair of tetralogy of Fallot. Eur J Cardiothorac Surg. 2013;43:336-42.

7. Bové T, François K, Van De Kerckhove K, Panzer J, De Groote K, De Wolf D, et al. Assessment of a right-ventricular infundibulum-sparing approach in transatrial-transpulmonary repair of tetralogy of Fallot. Eur J Cardiothorac Surg. 2012;41:126-33.

8. Puranik R, Tsang V, Lurz P, Muthurangu V, Offen S, Frigiola A, et al. Long-term importance of right ventricular outflow patch function in patients with pulmonary regurgitation. J Thorac Cardiovasc Surg. 2012;143:1003-7.

9. Eyskens B, Brown SC, Claus P, Dymarkowski S, Gewillig M, Bogaert J, et al The influence of pulmonary regurgitation on regional right ventricular function in children after surgical repair of tetralogy of Fallot. Eur J Echocardiogr 2010;11:341-5. 
10. Brown JW, Ruzmetov M, Vijay P, Rodefeld MD, Turrentine MW. Right ventricular outflow tract reconstruction with a polytetrafluoroethylene monocusp valve: a twelve-year experience. J Thorac Cardiovasc Surg. 2007;133:1336-43.

11. Bigras JL, Boutin C, McCrindle BW, Rebeyka IM. Short-term effect of monocuspid valves on pulmonary insufficiency and clinical outcome after surgical repair of tetralogy of Fallot. J Thorac Cardiovasc Surg. 1996;112:33-7.

12. Bogers AJ, Roofhooft M, Pisters H, Spitaels SE, Bos E. Long-term results of the gamma-irradiation-preserved homograft monocusp for transannular reconstruc tion of the right-ventricular outflow tract in tetralogy of Fallot. Thorac Cardiovasc Surg. 1994:42:337-9.

13. Gundry SR, Razzouk AJ, Boskind JF, Bansal R, Bailey LL. Fate of the pericardial monocusp pulmonary valve for right ventricular outflow tract reconstruction. J Thorac Cardiovasc Surg. 1994;107:908-13.

14. Edmunds LH, Saxena NG, Friedman S, Raskind WJ, Dodd PF. Transatrial repair of tetralogy of Fallot. Surgery. 1976;80:681-8.

15. Anagnostopoulos P, Azakie A, Natarajan S, Alphonso N, Brook MM, Karl TR. Pulmonary valve cusp augmentation with autologous pericardium may improve early outcome for tetralogy of Fallot. J Thorac Cardiovasc Surg. 2007;133: 640-7.

16. van den Berg J, Wielopolski PA, Meijboom FJ, Witsenburg M, Bogers AJ, Pattynama PM, et al. Diastolic function in repaired tetralogy of Fallot at rest and during stress: assessment with MR imaging. Radiology. 2007;243:212-9.

17. Lee C, Lee CH, Kwak JG, Song JY, Shim WS, Choi EY, et al. Bicuspid pulmonary valve implantation using polytetrafluoroethylene membrane: early results and assessment of the valve function by magnetic resonance imaging. Eur J Cardiothorac Surg. 2013;43:468-72.

18. Sasson L, Houri S, Sternfeld AR, Cohen I, Lenczner O, Bove EL, et al. Right ventricular outflow tract strategies for repair of tetralogy of Fallot: effect of monocusp valve reconstruction. Eur J Cardiothorac Surg. 2013;43:743-51.

19. Pande S, Agarwal SK, Majumdar G, Chandra B, Tewari P, Kumar S. Pericardial monocusp for pulmonary valve reconstruction: a new technique. Asian Cardiovasc Thorac Ann. 2010;18:279-84.

20. Robinson JD, Rathod RH, Brown DW, Del Nido PJ, Lock JE, McElhinney DB, et al. The evolving role of intraoperative balloon pulmonary valvuloplasty in valve-sparing repair of tetralogy of Fallot. J Thorac Cardiovasc Surg. 2011; $142: 1367-73$.

21. Bautista-Hernandez V, Cardenas I, Martinez-Bendayan I, Loyola H, Rueda F, Portela F. Valve-sparing tetralogy of Fallot repair with intraoperative dilation of the pulmonary valve. Pediatr Cardiol. 2013;34:918-23.

22. Vida VL, Padalino MA, Maschietto N, Biffanti R, Anderson RH, Milanesi O, et al. The balloon dilation of the pulmonary valve during early repair of tetralogy of Fallot. Catheter Cardiovasc Interv. 2012;80:915-21.

23. Bacha E. Valve-sparing options in tetralogy of Fallot surgery. Semin Thorac Cardiovasc Surg Pediatr Card Surg Annu. 2012;15:24-6.

24. Padalino MA, Vida VL, Stellin G. Transatrial-transpulmonary repair of tetralogy of Fallot. Semin Thorac Cardiovasc Surg Pediatr Card Surg Annu. 2009;48-53.

25. Bacha EA, Marshall AC, McElhinney DB, del Nido PJ. Expanding the hybrid concept in congenital heart surgery. Semin Thorac Cardiovasc Surg Pediatr Card Surg Annu. 2007;146-50.

26. Hua Z, Li S, Wang L, Hu S, Wang D. A new pulmonary valve cusp plasty technique markedly decreases transannular patch rate and improves midterm outcomes of tetralogy of Fallot repair. Eur J Cardiothorac Surg. 2011;40:1221-6.

27. Stewart RD, Backer CL, Young L, Mavroudis C. Tetralogy of Fallot: results of a pulmonary valve-sparing strategy. Ann Thorac Surg. 2005;80:1431-8.

28. Parameter (z). Echo Z-score calculators. http://parameterz.blogspot.com/2008/ 09/cardiac-valve-Z-scores.htm. Accessed November 11, 2013.

29. Puchalski MD, Askovich B, Sower CT, Williams RV, Minich LL, Tani LY. Pulmonary regurgitation: determining severity by echocardiography and magnetic resonance imaging. Congenit Heart Dis. 2008;3:168-75.

30. Grothoff M, Spors B, Abdul-Khaliq H, Gutberlet M. Evaluation of postoperative pulmonary regurgitation after surgical repair of tetralogy of Fallot: comparison between Doppler echocardiography and MR velocity mapping. Pediatr Radiol. 2008;38:186-91.

31. Horton KD, Meece RW, Hill JC. Assessment of the right ventricle by echocardiography: a primer for cardiac sonographers. J Am Soc Echocardiogr. 2009;22: 776-92.

32. Anavekar NS, Gerson D, Skali H, Kwong RY, Yucel EK, Solomon SD. Twodimensional assessment of right ventricular function: an echocardiographicMRI correlative study. Echocardiography. 2007;24:452-6.

33. Barron D. Tetralogy of Fallot: controversies in early management. World J Pediatr Congenital Heart Surg. 2013;4:186-91.
34. Dirks V, Pretre R, Knirsh W, Valsangiacomo Buechel ER, Seifert B, Schweiger M, et al. Modified Blalock-Taussig shunt: a not-so-simple palliative procedure. Eur J Cardiothorac Surg. 2013;44:1096-102.

35. Lucas V. Is bigger always better? Pulmonary artery growth after arterial duct stent: univentricular palliation, bridge to complete repair and definitive therapy. Catheter Cardiovasc Interv. 2009;74:1077.

\section{Discussion}

Dr Frank Hanley (Stanford, Calif). Dr Vida and his colleagues have addressed an important issue, that is, maximizing maintenance of pulmonary valve annular integrity during tetralogy of Fallot repair. There is a long history focusing on maintenance of pulmonary valve annular integrity in tetralogy of Fallot dating back to the early work of John Kirklin, who primarily focused on $\mathrm{Z}$ scores alone.

Over the years many technical maneuvers have been suggested to improve the percentage of patients in whom the annulus is preserved. In recent years, the introduction of intraoperative balloon dilation of the annulus has been introduced as one of these options, somewhat parallel to Hegar dilation or other forms of dilation of the valve. Several publications since 2007 have retrospectively assessed the potential benefit of this technique.

This study by Dr Vida and his colleagues is the first to incorporate at least some degree of prospective design. The authors prospectively assigned cohorts of patients either to receive or not to receive an intraoperative balloon procedure versus the standard treatment. And they used a predefined anatomic characteristic, the size of the pulmonary annulus preoperatively, to determine which group the patients would belong.

The results are encouraging that this may be a useful technique and the study is an important contribution. There are, however, uncertainties and significant limitations with respect to drawing definitive conclusions based on the results. I have a few questions that address those potential limitations.

The first relates to study design. It seems unfortunate that you did not match the patients based on their pulmonary valve annular size. So as it turns out, you have picked a favorable anatomic group who get the preservation and a more unfavorable anatomic group that received the standard technique, so you can see where a potential bias would be present in the long-term results. Why did you not decide to do a matched control of the pulmonary valve annular size and just randomize matched patients into those 2 groups? It would have been easy to do.

Dr Vida. We started to apply this technique a few years ago. At the beginning, we decided to start with milder forms of tetralogy of Fallot with less severe pulmonary valve $\mathrm{Z}$ scores. As we have gained more experience with this new technique, we have been treating even more severe forms of tetralogy of Fallot.

Our initial limit for choosing the balloon dilation technique was a pulmonary valve $\mathrm{Z}$ score equal to or more than -3 , and this, at the beginning, was surgeon dependent. In the last couple of years, with the advent of more aggressive additional pulmonary valve plasty techniques, such as leaflet delamination, we decided to be more aggressive, applying this technique in patients with a $Z$ score as low as -4 .

Initially, we had a tendency to oversize our balloon catheters during the pulmonary valve dilation phase, based on the 
experience from the catheter laboratory, where our cardiologist colleagues usually go up to $120 \%$ to $150 \%$ of the initial pulmonary valve diameter. However, we have learned that, to avoid unexpected tears of the pulmonary valve leaflet or annulus during the dilation, it is better to dilate the annulus up to the expected normal value for the patient's body surface area by using high-pressure noncompliant balloons.

As you pointed out, 1 of the major limitations of this study is that it is not a prospective randomized clinical trial. We analyzed our patient population in a retrospective fashion, comparing patients who underwent pulmonary valve preservation with patients who underwent a standard transatrial/transpulmonary repair technique.

Looking back at our results, we were able to preserve almost half of the pulmonary valves in our patients with tetralogy of Fallot. However, we can speculate, considering the latest achievements with this technique, that we could have saved more valves during the early stages of our experience, potentially saving the pulmonary valve in up to the $75 \%$ of our patients.

Dr Hanley. So I mean clearly this was more learn-as-you-go than prospectively designing. The read of the paper, in all fairness, sounds a little bit more like it was prospectively set up that way. But we have all been there, and learning as we go is a good technique, I am not criticizing that at all.

Another question relates to the follow-up. There is a discrepancy in the median follow-up periods for the 2 groups, and it is large: 433 days for the balloon group and 712 for the other group. And importantly, over the 433 days of follow-up for the preservation group, the percentage of patients who developed significant regurgitation almost doubled from $11.8 \%$ to $20 \%$. A skeptic I guess could argue that if the preservation group was allowed to go out to 712 days, almost another 300 days, if there was another point on the curve, there was probably going to be a significant increase further, because it has already been demonstrated there has been some, a further increase in the amount of regurgitation, and would it be different than the control group?

Dr Vida. Yes, the follow-up time is different between out study groups. In fact, as we became more familiar with the pulmonary valve preservation technique, we were able to preserve most pulmonary valves during early repair of tetralogy of Fallot, especially in the last few years; this contributed to the shorter follow-up time in the preservation group.

Nonetheless, the shorter postoperative follow-up time, and because we are still in a learning phase with this new technique, our results are encouraging. In fact, most patients in the preservation group, almost $90 \%$, were discharged home with none to trivial pulmonary valve regurgitation. Only a few of them, all with severe forms of tetralogy of Fallot, had a moderate degree of pulmonary valve regurgitation.

On the contrary, when we used an artificial cusp to achieve pulmonary valve competence during transannular patch repair, we have since the beginning had a higher frequency of more severe forms of valve regurgitation, which progressed over time in most patients.

Dr Hanley. Absolutely. You have clearly shown that short term you come up with less regurgitation. I guess the concern is way further out.
One last brief question. For what percentage of the patients in the preservation group did you use artificial material on the patch? Because I would say, and I will not respond after, but my concern there is the more you use artificial material on a young infant, pulmonary valve or any valve, the more likely you are going to have failure later.

Dr Vida. We needed to use biological material in 4 patients during pulmonary valve preservation. All these patients had more severe forms of tetralogy of Fallot, with an initial $\mathrm{Z}$ score less than -3.5 . These patches were used to further extend the pulmonary valve leaflet coaptation area after balloon dilation and leaflet delamination, in order to achieve optimal valve competence.

Dr Christopher A. Caldarone (Toronto, Ontario, Canada). You bring up a novel concept, this concept of the delamination to extend the size of the pulmonary valve leaflets, and I think that would warrant some more discussion in terms of what the limits are to that technique and there may be a few tips that you may have in that regard. Can you just give us the briefest of comments on that.

Dr Vida. The pulmonary valve in patients with tetralogy of Fallot is usually thick and dysplastic and in most cases bicuspid. Following balloon dilation, a gap in the valvular tissue is usually present at 1 commissure level. In order to fill this gap and to make that valve competent, we extend the pulmonary leaflets by delaminating them at the hinge point level down to the right ventricular myocardium.

After delamination, a good coaptation between leaflets is usually achieved, however leaflets are usually prolapsing and need to be resuspended recreating a new commissure. If the leaflet is too short after delamination, the risk is a decrease in its motion after resuspension. To avoid the creation of a still, immobile leaflet, we decided to extend 1 leaflet end by means of a prosthetic patch. An initial concern deriving from the delamination process was possible right ventricular muscle blood infiltration. However, it did not happen in our patients, possibly because the delaminated site is exposed to the pressure of the pulmonary district, which is usually low in patients with tetralogy of Fallot.

Dr Caldarone. It is very interesting.

Dr Emile Bacha (New York, NY). Nice work. As you know, I am a proponent of the technique, but I have given it up for the severe end of the spectrum of tetralogy of Fallot. I do not use it anymore for very low $\mathrm{Z}$ scores or severely stenotic valves. I use it for the moderate range of $\mathrm{Z}$ scores up to $-2.5,-3$. I do not really like to use $\mathrm{Z}$ score either because it does not take into account the morphology of the pulmonary valve, and only measures the annular size with no accounting for the effective orifice and the cusp morphology.

However, it seems to me what you are doing is using a balloon as only 1 of the steps in your management of your severe tetralogy of Fallot spectrum. You are using patches, you are putting stitches in the valve. And so I would agree with Dr Hanley's comment that probably what you are going to see long term is more pulmonary regurgitation developing because you have instrumented this valve so much by necessity. And in my view, I would rather do a controlled surgical intervention on a severely stenotic valve, such as dividing it where I want to, as opposed to having a balloon 
with a somewhat nondiscriminate tear of the valve, and then reconstruct this valve.

Dr Vida. Well, I agree with you. This treatment is appealing for milder forms of tetralogy of Fallot with a pulmonary valve $\mathrm{Z}$ score of -3 or higher. With the advent of a more aggressive approach, we were able to treat more severe forms, and, so far, have achieved good mid-term results. These results are significantly superior to the results from our standard transatrial/transpulmonary approach. However, a longer follow-up is certainly mandatory to prove the efficacy of this technique.

Dr Bacha. I do not disagree with plasty for the valve and working on the valve trying to preserve it. But I am saying that, at the severe end of the spectrum, you probably have more control over what you do with this valve if you divide it where you want it, as opposed to introducing a balloon. The valve may tear in a place that you do not want it to tear.

Dr Vida. Because of its high success rate, our current policy is to attempt the preservation of the pulmonary valve in every single patient during repair of tetralogy of Fallot. This technique guarantees superior results in terms of pulmonary valve competence at discharge compared with our standard repair. In cases where the pulmonary valve cannot be preserved, these patients can be easily converted to the standard approach without additional risk. 